\title{
The Context of the Covid-19 Pandemic and its Effect on the Self-Perception of Professional Competences by University Students of Business Administration
}

Nestor Alvarado-Bravo ${ }^{*}, 1$, Florcita Aldana-Trejo ${ }^{2}$, Almintor Torres-Quiroz ${ }^{1}$, Carlos Aliaga-Valdez ${ }^{1}$, William Angulo-Pomiano ${ }^{3}$, Frank Escobedo-Bailón ${ }^{4}$, Katherin Rodriguez-Zevallos ${ }^{5}$, Carlos Dávila-Ignacio ${ }^{4}$, Omar Chamorro-Atalaya ${ }^{4}$

${ }^{1}$ University National of Callao, Faculty of Chemical Engineering, Faculty of Economic Sciences, and Faculty of Administrative Sciences, Callao, 07001, Perú

${ }^{2}$ Federico Villareal National University, Faculty of Economic Sciencies, Lima, 15011, Perú

${ }^{3}$ Peruvian University of the Americas, Faculty of Business, Lima, 15011, Perú

${ }^{4}$ National Technological University of Lima Sur, Faculty of Engineering and Management, Lima, 15011, Perú

${ }^{5}$ Huánuco University, Faculty of Health Sciences, Huánuco, 07051, Perú

A R T I C L E I N F O

Article history:

Received: 24 January, 2021

Accepted: 13 March, 2021

Online: 20 March, 2021

Keywords:

Self-perception

Professional skills

Business Administration

Pandemic

Covid-19

\begin{abstract}
A B S T R A C T
This article aims to determine to what extent the self-perception of acquiring professional skills has been affect ed, by the context of the Covid-19 pandemic in University Students of Business Administration; For which, the results obtained in two satisfaction survey processes, carried out in academic semesters 2019-B and 2020-A, have been compared, marking a before and after in relation to the declaration of a state of emergency in Peru. Initially, it was determined that the indicators "To solve specialty cases" and "To assume self-education" are the most affected in this dimension, with a percentage of decrease in satisfaction of $3.42 \%$ and $3.82 \%$, respectively. Then it was determined through the use of the statistical analysis of crossed tables, that the percentage of totally dissatisfied students, in the self-perception of having acquired the competences referred to the two indicators with the greatest negative impact, has remained invariant, almost constant, around of $44 \%$. With this, it can be concluded that the self-perception of acquiring professional skills has been affected, by the context of the Covid-19 pandemic, decreasing by $3.1 \%$, student satisfaction, as observed in the two indicators with the greatest impact negative "To assume self-education", and "To solve specialty cases". These results will allow the Public University of Peru to establish improvement plans, in order to advance towards the development of the teaching-learning model in a virtual way in higher education.
\end{abstract}

\section{Introduction}

Society has seen the need to adapt in multiple areas to an unexpected enemy; In the study of [1], it is pointed out that this unexpected enemy has affected the way in which living beings coexist in a society, and within this is the University community and its learning. Likewise, in the research of [2] it states that more than 1,500 million university students, from 165 countries, were unable to attend learning centers, due to the Covid-19 pandemic.

${ }^{*}$ Corresponding Author: Nestor Alvarado-Bravo, Mz. K Lote 22, Urb. La Estancia de Carabayllo, Distrito de Carabayllo, 951201999, nmalvaradob@unac.edu.pe

www.astesj.com

https://dx.doi.org/10.25046/aj060277
In the study of [3], it is specified that the context of Covid-19, from one day to the next, led the university student to be forced to change the classrooms for rooms in their houses, replacing the learning contents, tasks and activities face-to-face through content based on virtual environments.

Given this [4], he points out that for the university student the circumstances generated by the Covid-19 pandemic imply changes that require capacities that, in many cases, may be underdeveloped to adapt to the type of virtual educational modalities.

In the research of [5], it is pointed out that many universities worldwide in the context of Covid-19, have seen the teaching665 
learning process affected, even more so in pedagogical aspects on the side of the teacher and the acquisition of competences by the student's side.

In the study of [6], a professional competence is defined as the ability of an individual to interact effectively with their environment, as long as it is learned, as part of a stepped process; competition is closely related to motivation or satisfaction.

In turn, the study of [7] affirms that in the face-to-face system the perception of satisfaction in relation to the acquisition of professional competences was influenced by learning based on direct social interactions, however, in the virtual system it is Perception can be further influenced by the lack of a fluid and direct dialogue.

In the research of [8], it is pointed out that, in the context of the pandemic, it is evident that many universities to adapt to this scenario have not carefully innovated the teaching-learning design, but rather in the process of developing the classes they have been adapted according to the circumstances, leaving aside the development of the student's competencies.

In the study of [9], the author agrees with what was said in the previous paragraph, in which he points out that we must be aware that in order to plan virtual courses, the ideal is to start preparing them much earlier (months in advance), in such a way that a learning process was designed that guarantees that students reach the competences of each subject; but this has not happened when the pandemic occurred.

In the same line of thought as the previous author, in the study of [10], it is pointed out that the context of the pandemic has not only made the existing deficiencies and major inequities more noticeable, which already made it difficult to achieve the achievement of competencies in the university students in the faceto-face context, has also brought to light the deficiencies of acquiring these skills through virtual environments.

In Peru, and through the Ministry of Education, ViceMinisterial Resolution No. 085-2020-MINEDU was promulgated, in which guidelines are given for the continuity of the university higher education service, in the framework of the health emergency caused by the covid-19; However, in the study of [11], it is pointed out that in Peru, it had to face the crisis in an abrupt and unexpected way.

However, even before the presence of the pandemic, there was the problem of the acquisition of skills by university students; In the study of [12], it is pointed out that university education currently poses significant challenges in the search for an education that contributes to the realization of a relevant society, responding to the needs of the labor and business system.

In this regard, in the study of [13], it is pointed out that the professional competences acquired by the students of the professional career of Business Administration turn out to be necessary for a correct development in the field of human talent management in organizations, the orientation of seeking that workers have key competencies so that companies are competitive is assumed.

Based on the above, the purpose of this article is to determine to what extent the self-perception of acquiring professional skills has been affected by the context of the Covid-19 pandemic; For which, the results obtained in two satisfaction survey processes, carried out in academic semesters 2019-B and 2020-A, will be compared, marking a before and after in relation to the declaration of a state of emergency in Peru. It will be sought to highlight which indicators of this dimension called self-perception of competences are the most affected, and whether there is coherence between the decrease or increase of these indicators, through the use of the statistical analysis of crossed tables, for qualitative data of nominal.

\section{Investigation methodology}

\subsection{Research design}

The research design is non-experimental, of a longitudinal trend type, because no alteration or modification of the variable was made, in order to see any effect on the sample under analysis; in non-experimental investigations the data is analyzed in its natural state.

In addition, it is of the longitudinal type of trend since the data to be collected were carried out in two different academic semesters (Before the declaration of pandemic- 2019-B, and after the declaration of pandemic- 2020-A).

The research level is descriptive, because the variables are not altered, and what is intended to highlight are the aspects related to the variation of the Self-perception of university students of Business Administration with respect to Professional Competences, which are established in the satisfaction survey of the Public University of Peru.

\subsection{Population and Sample}

The population will be made up of university students from the seventh to the tenth cycle of the professional school of Business Administration, enrolled in the academic semester 2019-B and 2020-A. Regarding what has been described [14], it indicates that students who are in the last four cycles of study are more aware of the perceptions in relation to the satisfaction of professional skills.

On the other hand, the sample under study will be made up of the entire population, since it was possible to apply the data collection instrument to the entire student population, without any distinction, this with the purpose or purpose of achieving better precision in obtaining results.

It should be noted that the data collection period is carried out at different times, and at different samples, because the number of students surveyed is not the same in the 2019-B semester, as in the 2020-A semester.

Table 1: Research population and sample

\begin{tabular}{|c|c|}
\hline Population & Sample \\
\hline $\begin{array}{c}\text { University students enrolled, from the seventh to the } \\
\text { tenth cycle - Business Administration 2019-B }\end{array}$ & 135 \\
\hline $\begin{array}{c}\text { University students enrolled, from the seventh to the } \\
\text { tenth cycle - Business Administration 2020-A }\end{array}$ \\
\hline
\end{tabular}


Table 1 shows precisely that the sample will be made up of 135 students from the 2019-B semester and 155 students from the 2020-A semester.

\subsection{Data Collection Technique and Instrument}

The technique used in the present investigation is the document analysis technique, and the instrument is a data record sheet. This is because the source I will turn to extract the data are reports from the student satisfaction survey reports for the academic semesters 2019-B and 2020-A, approved by the office of academic and prospective management, of a university state in Peru.

It is important to note that the record sheet used as a data collection instrument takes as a variable to analyze the selfperception of professional competences, which in turn consists of ten indicators, the same ones shown in Table 2.

Table 2: Indicators of self-perception of professional skills

\begin{tabular}{|c|c|}
\hline $\mathrm{N}^{\circ}$ & Indicators of self-perception of skills \\
\hline 1 & To work as a team \\
\hline 2 & To solve problems and cases of the specialty \\
\hline 3 & To act with autonomy and initiative \\
\hline 4 & To confront your own ideas with others \\
\hline 5 & To speak in public with appropriate language \\
\hline 6 & To have a positive attitude towards change \\
\hline 7 & Assume a self-study \\
\hline 8 & To master practical professional skills \\
\hline 9 & To work under pressure \\
\hline 10 & To have investigative powers \\
\hline
\end{tabular}

Likewise, the data collected was processed and transformed, initially using the scale of attitudes and opinions, known as the Likert scale; Since the questionnaire has two self-perception options to choose from, being dissatisfied and satisfied, each one was valued with the numeral 1 and 2, respectively.

It should be taken into account that for the statistical analysis of crossed tables, the Chi-Square test will be carried out, in order to validate the hypothesis, which indicates the association between the variables under study. It should be noted that usually, H0 indicates that both variables are independent, while $\mathrm{H} 1$ indicates that the variables have some degree of association.

Described in the previous paragraph, we proceed to establish the null hypothesis (Ho) and alternative (Ha) that will be used in the investigation.

Ho: The self-perception of acquiring professional skills has not been affected, by the context of the Covid-19 pandemic.

Ha: The self-perception of acquiring professional skills has been affected, by the context of the Covid-19 pandemic

\section{Research Results}

The data collected were subjected to a validity analysis through Cronbach's alpha. It should be noted that since two different scenarios were worked, that is, one scenario is in the context of face-to-face classes, that is, before the declaration of the state of health emergency by Covid-19 (Semester 2019-B) and the other scenario It is the context of virtual classes (Semester 2020-A). Table 3 shows the results of Cronbach's alpha.

Table 3: Validation of collected data - Cronbach's Alpha

\begin{tabular}{|c|c|}
\hline $\begin{array}{c}\text { Validation of collected data } \\
\text { Cronbach's alpha }\end{array}$ & Cronbach's Alpha \\
\hline Self-perception of professional competences 2019-B & 0.938 \\
\hline Self-perception of professional competences 2020-A & 0.908 \\
\hline
\end{tabular}

\subsection{Comparative analysis of the Indicators of the self-perception of professional competences}

In the comparative analysis of the percentage of satisfaction of the indicators of self-perception of professional competence before (semester 2019-B) and after (semester 2020-A) of the declaration of a state of health emergency due to the pandemic, it can be seen in the Figure 1, that the indicators that show a greater negative impact or decrease in satisfaction as an effect of carrying out the teaching-learning process in a virtual way, are the indicator "To solve cases of the specialty", with a percentage of decrease in satisfaction of $3.42 \%$, while the other indicator is "To assume a self-education", with a percentage of decrease in satisfaction of $3.82 \%$; The analysis will basically focus on these two indicators, since in the other cases it is observed that the level of negative impact with respect to the level of satisfaction is below $2.5 \%$, that is, it is relatively lower in relation to the high levels shown Most of the indicators that make up the self-perception variable, whose satisfaction level before the pandemic was in the range of $80.74 \%$ and $89.63 \%$, while after the declaration of the pandemic it is in the range of $79.35 \%$ and $87.10 \%$; As i emphasize again, these values are above the average for student satisfaction in general, which is $63 \%$.

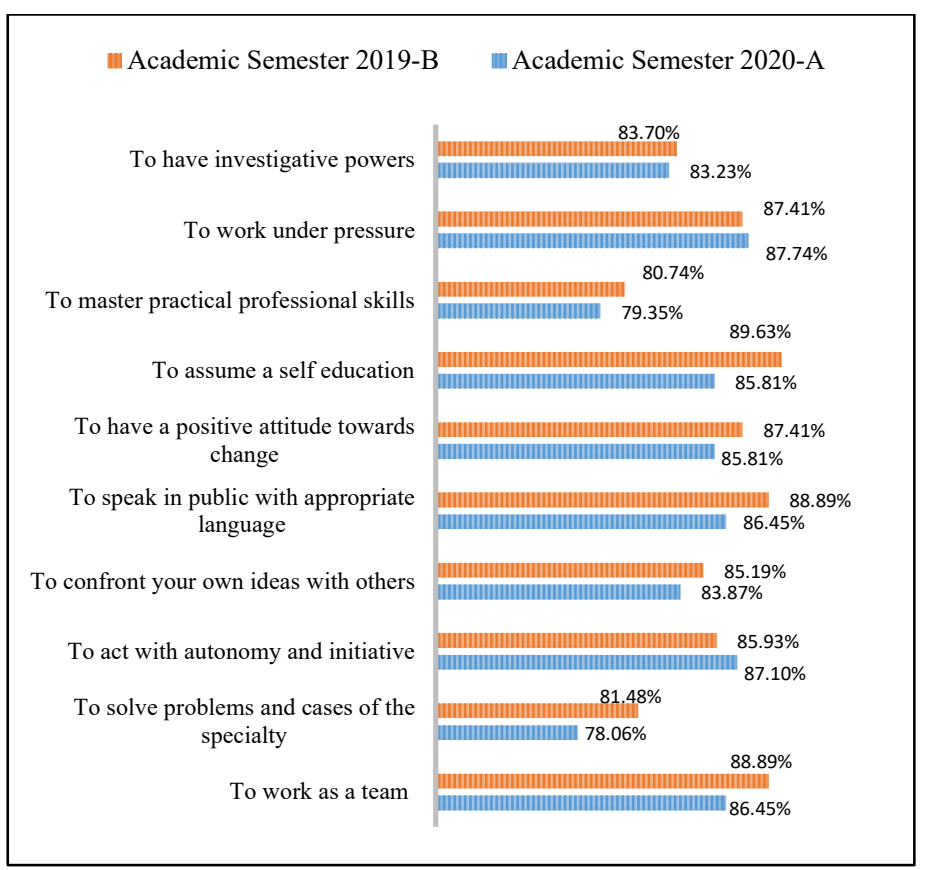

Figure 1: Comparison of the percentage of satisfaction of the indicators of selfperception before and after the declaration of the COVID-19 pandemic 
Next, we will proceed to verify if there is an association between these two indicators, through the statistical analysis by cross table. This analysis will be carried out by academic semester, that is, before and after the declaration of the state of health emergency.

\subsection{Level of association of indicators with the greatest negative impact on self-perception}

The results of the chi square test are shown below, to determine the association between the variables.

Table 4: Chi-square test

\begin{tabular}{|l|r|r|r|}
\hline & Value & \multicolumn{1}{|c|}{ gl } & \multicolumn{2}{|c|}{$\begin{array}{c}\text { Continuity } \\
\text { correction }\end{array}$} \\
\hline Pearson's Chi-square & 32,023 & 1 &, 000 \\
\hline Continuity correction & 28,952 & 1 &, 000 \\
\hline
\end{tabular}

As can be seen in Table 4, the value of the Chi-square statistic is 32.023 and the continuity correction is 28.952; Regarding these indicators, it has been established according to different authors that they are valid when the value of an expected frequency is greater than 5, for significance levels greater than 0.05; as described and as shown in the table above, for both cases, the test results comply with what is established.

On the other hand, the significance (bilateral) of the Chi-square is 0.000; This value is less than the level of significance, $\alpha=0.05$, according to different authors, if the observed results are greater than $\alpha=0.05$, that is, they differ from what is theoretically established, it is possible to reject Ho and affirm that Ha is true, concluding that the variables are associated. On the contrary, if the observed results do not differ significantly, that is, the bilateral significance is less than and equal to alpha, the veracity of $\mathrm{HO}$ is confirmed and it is affirmed that the variables are independent.

With what was obtained, it would be validating that the selfperception of acquiring professional skills has been affected, by the context of the Covid-19 pandemic. Once this association has been verified, the level of association of the indicators with the greatest negative impact on self-perception will be determined, which were identified in the previous point 3.1 .

Using the statistical software SPSS v25, the results obtained from the descriptive analysis are shown below through cross tables; This is due to the fact that the indicators represent qualitative data related to student satisfaction and dissatisfaction, corresponding to the indicators with the greatest negative impact or decrease with respect to the self-perception of professional skills, identified in the previous section.

Table 5: Cross table - to assume a self-education and to solve problems and cases of the specialty-2019 B

\begin{tabular}{|c|c|c|c|c|}
\hline & & \multicolumn{2}{|c|}{$\begin{array}{l}\text { To solve problems and } \\
\text { cases of the specialty, } \\
\text { 2019-B }\end{array}$} & \multirow[t]{2}{*}{ Total } \\
\hline & & Dissatisfied & Satisfied & \\
\hline \multirow{2}{*}{$\begin{array}{l}\text { To assume a self- } \\
\text { education, 2019-B }\end{array}$} & Dissatisfied & $44.0 \%$ & $2.7 \%$ & $10.4 \%$ \\
\hline & Satisfied & $56.0 \%$ & $97.3 \%$ & $89.6 \%$ \\
\hline Total & & $100.0 \%$ & $100.0 \%$ & $100.0 \%$ \\
\hline
\end{tabular}

From Table 5, it can be seen that before the declaration of the state of health emergency due to the pandemic (academic semester 2019-B), 44\% of students from the professional school of Business Administration were dissatisfied with the self-perception of having acquired professional competences referred to "To assume a selfeducation", as well as "To solve cases of the specialty"; While $97.3 \%$ of students from the professional school in question, were satisfied with respect to the self-perception of having acquired professional competencies referred to "To assume a selfeducation", as well as "To solve cases of the specialty".

As can be seen in Table 5, it shows us the results as a percentage, while the following table 6 shows the count of satisfaction and dissatisfaction, of the 135 students of the semester 2019-B, who have the same relationship between their perception and the self-perception of having acquired skills. professionals referred to "To assume a self-education", as well as "To solve cases of the specialty"

Table 6: Cross counting table - to assume a self-education and to solve problems and cases of the specialty-2019 B

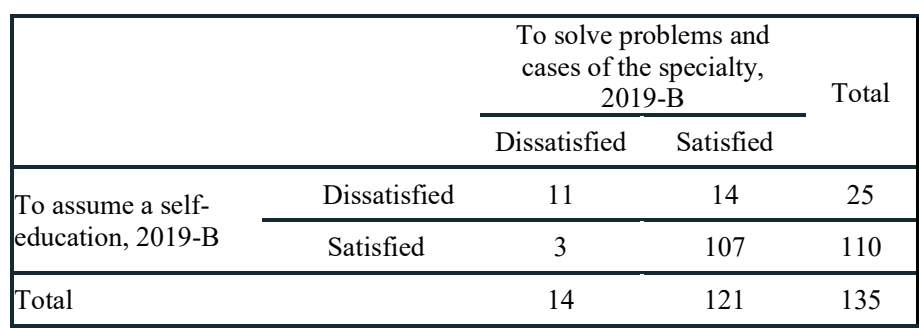

Figure 2 shows the representation of the results obtained.

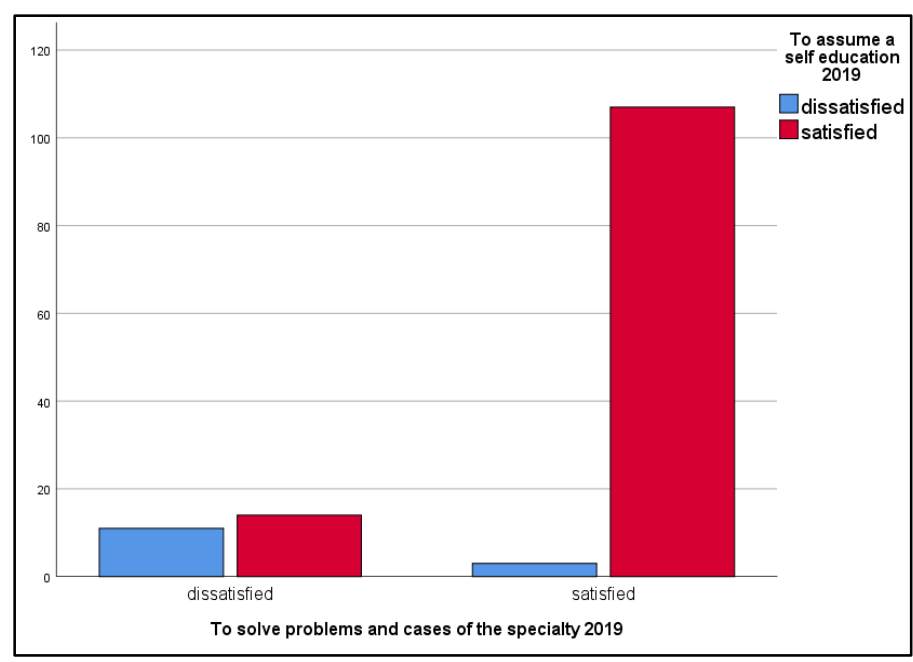

Figure 2: Indicator association count to assume a self-education and to solve problems and cases of the specialty-2019 B

As can be seen in Figure 2, and according to the count of the total of 135 business administration students, 11 students were dissatisfied with the self-perception of having acquired professional competences referred to "To assume a selfeducation", as well as "To resolve specialty cases" and 107 students were satisfied with these two indicators.

From table 7, it is observed that after the declaration of the state of health emergency due to the pandemic (academic semester 2020-A), 44.1\% of students of the professional school of Business Administration were dissatisfied with the self-perception of having 668 
acquired professional skills referred to "To assume a selfeducation", as well as "To solve cases of the specialty"; While $94.2 \%$ of students from the professional school in question were satisfied with respect to the self-perception of having acquired professional competencies referred to "To assume a selfeducation", as well as "To solve cases of the specialty".

Table 7: Cross table - to assume a self-education and to solve problems and cases of the specialty, 2020-I

\begin{tabular}{|lcccc|}
\hline & & \multicolumn{3}{c|}{$\begin{array}{l}\text { To solve problems and } \\
\text { cases of the specialty, }\end{array}$} \\
\cline { 2 - 4 } & & \multicolumn{2}{c|}{ 2020-A } & Total \\
\cline { 2 - 4 } & Dissatisfied & Satisfied & \\
\hline $\begin{array}{l}\text { To assume a self- } \\
\text { education, 2020-A }\end{array}$ & Dissatisfied & $44.10 \%$ & $5.8 \%$ & $10.4 \%$ \\
\cline { 2 - 4 } Total & Satisfied & $55.90 \%$ & $94.2 \%$ & $89.6 \%$ \\
\hline
\end{tabular}

As can be seen in Table 7, it shows us the results as a percentage, while the following table 8 shows the count of satisfaction and dissatisfaction, of the 155 students of the semester 2020-A, who have the same relationship between their perception and the self-perception of having acquired skills. professionals referred to "To assume a self-education", as well as "To solve cases of the specialty". In the figure 3 shows the representation of the results obtained.

Table 6: Cross counting table - to assume a self-education and to solve problems and cases of the specialty-2020 A

\begin{tabular}{|c|c|c|c|c|}
\hline & & \multicolumn{2}{|c|}{$\begin{array}{c}\text { To solve problems and } \\
\text { cases of the specialty, } \\
2020-\mathrm{A}\end{array}$} & \multirow[t]{2}{*}{ Total } \\
\hline & & Dissatisfied & Satisfied & \\
\hline \multirow{2}{*}{$\begin{array}{l}\text { To assume a self- } \\
\text { education, } 2020-\mathrm{A}\end{array}$} & Dissatisfied & 11 & 14 & 25 \\
\hline & Satisfied & 3 & 107 & 110 \\
\hline Total & & 14 & 121 & 135 \\
\hline
\end{tabular}

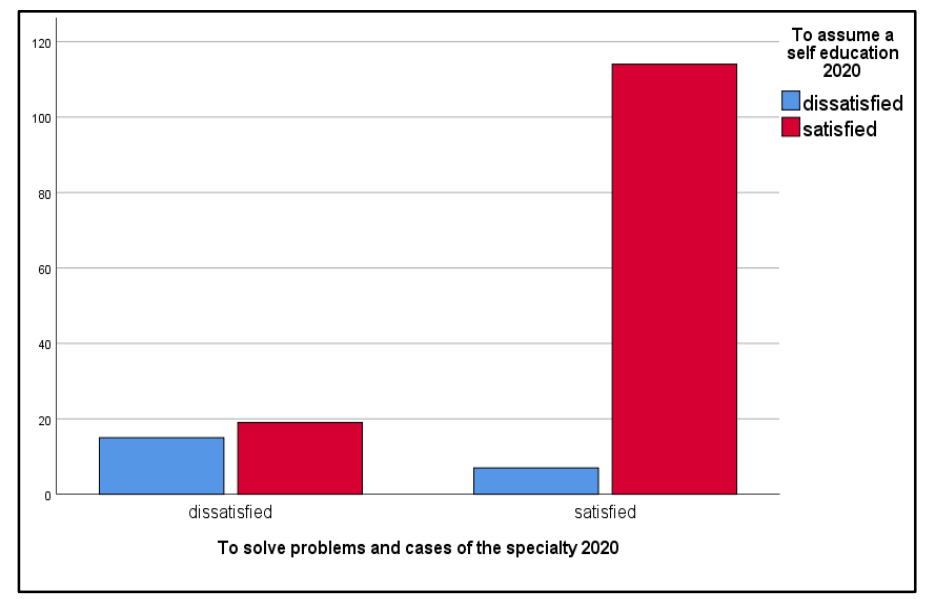

Figure 3: Indicator association count to assume a self-education and to solve problems and cases of the specialty-2020 A

As can be seen in the figure 3 and according to the count of the total of 155 business administration students, 15 students were dissatisfied with the self-perception of having acquired professional competences referred to "To assume a selfeducation", as well as "To resolve specialty cases" and 114 students were satisfied with these two indicators.

Thus, it can also be observed that the percentage of students from the professional school of Business Administration, who were previously fully satisfied in the self-perception of having acquired professional skills referred to "To assume a selfeducation", as well as "To solve cases of the specialty ", Has had a negative impact, as an effect of the teaching of classes through virtual platforms, since it has decreased by $3.1 \%$, while the percentage of totally dissatisfied students, in the self-perception of having acquired the aforementioned competences, has been kept invariant, almost constant, at around $44 \%$.

\section{Discussion of results}

In relation to the discussion of the results, the following can be specified:

- The results show that the indicators that show a greater negative impact or decrease in satisfaction as an effect of carrying out the teaching-learning process in a virtual way, are the indicator "To solve cases of the specialty", and the indicator "To be assumed a self-education". Regarding this, in the study of [15] it is indicated that, in the career of business administration, professional competences are used as an organizing principle, and they serve to face the types of situations that students have to be capable of. solve effectively in the workplace; Therefore, the great importance of teamwork, as an organizational set, will have a positive impact on the internal logic of the business world.

- Regarding the result, where it is indicated that the percentage of students of the professional school of Business Administration, who before were totally satisfied in the selfperception of having acquired professional skills referred to "To assume a self-education", as well as "To solve cases of the specialty", has had a negative impact, as an effect of the teaching of classes through virtual platforms, decreasing by $3.1 \%$. Given this, it can be argued that these two indicators are affected, with respect to student satisfaction, because, in virtual classes, they are not getting to work, an essential factor, such as the development of skills and competencies, which through face-to-face learning, was obtained through teamwork, which allowed students to communicate effectively, function, transmit new ideas, show their creativity; which leads to generating in each one their leadership style and their positive influence on others. As indicated in the study of [16], administration professionals define that teamwork is highly valued in today's companies, and that it is necessary for the collaborator to contribute intellectual capital to the company and to the development of the human team that make up.

- Regarding the result that shows us that the percentage of totally dissatisfied students, in the self-perception of having acquired the skills referred to "To assume a self-education", as well as "To solve cases of the specialty", through the teaching of classes through of virtual platforms has remained invariant, almost constant, at around $44 \%$. It can be indicated that students perceive these extremely important 
competencies, and in both teaching-learning scenarios, there have not been updated information and communication technology tools, used in administrative management, marketing planning and strategic planning, tactical and operational. Regarding this, in the study of [7], it is indicated that the administrative technological tools have the objective of guiding the methodological and didactic actions, which allow not only to improve the cognitive system, but also the qualities and principles of the student. of administration.

- Given the results obtained, it can be said that they resemble the study carried out by [16] where it is stated that there is a (bilateral) significance lower than $\alpha=0.05$, therefore it can be statistically supported that there is a significant association between the Analyzed indicators, Since, when the student feels with the ability to master practical professional skills, it becomes much easier for him to solve problems and cases of the specialty, thus being able to present himself in front of the labor market.

\section{Conclusions}

In relation to the conclusions, the following is specified:

- The self-perception of acquiring professional skills has been affected, by the context of the Covid-19 pandemic, decreasing by $3.1 \%$, student satisfaction, as observed in the two indicators with the greatest negative impact "To assume a selfeducation", and "To solve specialty cases".

- The indicators that show a greater negative impact or decrease in satisfaction as an effect of carrying out the teachinglearning process in a virtual way, are the indicator "To solve cases of the specialty", with a percentage of decrease in satisfaction of $3.42 \%$, while the other indicator is "To assume a self-education", with a percentage decrease in satisfaction of $3.82 \%$.

- The statistical analysis of crossed tables shows us that the percentage of totally dissatisfied students, in the selfperception of having acquired the skills referred to "To assume a self-education", as well as "To solve cases of the specialty", through the dictation of classes through virtual platforms has remained invariant, almost constant, at around $44 \%$.

\section{Conflict of Interest}

The authors declare no conflict of interest.

\section{References}

[1] M. Causa, K. Lastra, "Public universities in the metropolitan region: some strategic lines of action to guarantee inclusion in the context of the Covid-19 pandemic," University Trajectories, 6(10), 1-17, 2020, doi: $10.24215 / 24690090 \mathrm{e} 29$.

[2] J. Cáceres-Muñoz, A. Jiménez, M. Sánchez, "School closures and socioeducational inequality in times of Covid-19," International Journal of Education for Social Justice, 9(3), 199-221, 2020, doi: 10.15366/RIEJS2020.9.3.011.

[3] M. Gutiérrez, J. Tomas, "Teaching support, academic commitment and satisfaction of university students," Studies on Education Journal, 35(3), 535-555, 2018, doi:10.15581/004.35.

[4] I. Ordorika, "Pandemic and Higher Education," High School Journal, 49(4), 1-8, 2020, doi: 10.36857/resu.2020.194.1120.
[5] L. Araujo, J. Ochoa, C. Vélez, "The chiaroscuro of the Ecuadorian university: the challenges in contexts of the Covid-19 pandemic," Digital Journal of University Research, 14(2), 1-17, 2020, doi: 10.19083/ridu. 2020.1241.

[6] C. Acosta, D. Ortega, Y. Díaz, "Face-to-face education with virtual mediation: an experience of Honduras in times of Covid-19," Digital Journal of Research in University Teaching, 14(2), 1-17, 2020, doi: 10.19083/ ridu.2020.1229.

[7] M. Castro, M. Paz, E. Cela, "Learning to teach in times of the Covid-19 pandemic: our experience in a public university in Argentina," Digital Research in University Teaching, 14(2), 1-17, 2020, doi: 10.19083/ridu.2020.1271.

[8] A. Ojeda-Beltrán, D. Ortega-Álvarez, E. Boom-Cárcamo, "Analysis of the perception of face-to-face students about virtual classes as a response to the Covid-19 crisis," Espacios Journal, 41(42), 81-92, 2020, doi: a20v41n42/20414207.

[9] F. Canaza-Choque, "Higher Education in the global quarantine: disruptions and transitions," Digital Journal of Research in University Teaching, 14(2), 1-17, 2020, doi: 10.19083/ridu.2020.1315.

[10] J. Vergara-Morales, M. Del Valle, A. Díaz, L. Matos, M. Pérez, "Motivational profiles related to the academic satisfaction of university students," Annals of Psychology Journal, 35(3), 464-471, 2019, doi: 10.6018/analesps.35.3.320441.

[11] M. Merino, "Professional profile of the administration career in a Peruvian university," Espacios Journal, 41(30), 216-231, 2020, doi: a20v41n30/20413018.

[12] W. Casimiro, C. Casimiro J. Casimiro, "Entrepreneurship competencies in university students, ”Universidad y Sociedad Journal, 11(5), 61-69, 2019.

[13] H. Torrez, M. Vilá, S. Cruz, "A competency-based co-evaluation approach in business administration studies," V International Congress on Learning, Innovation and Competitiveness, 166-171, 2019, doi:10.26754/CINAIC.2019.0036.

[14] M. Tobón, M. Durán, A. Añez, "Academic and Professional Satisfaction of University Students," REDHECS Journal, 22(11), 110-129, 2016.

[15] M. Mirko, "Professional profile of the administration career in a Peruvian university," Espacios Journal, 41(30), 216-231, 2020, doi: http://orcid.org/0000-0002-8820-6382.

[16] R. Benites, J. Chica, "Graduation and Employability: Students' Perception about their University Education in Business Administration” Hallazgos21 Journal, 2(2), 108-119, 2017, 